\title{
Control and Simulation Analysis on Grid Side of a Doubly-Fed Induction Generator Wind Turbine using Different Controllers
}

\author{
Adarsh. C. Anand ${ }^{1}$ | Dr. J. Vijaya Kumar ${ }^{2}$ \\ ${ }^{1}$ Department of Electrical Engineering, Anil Neerukonda Institute of Technology and Sciences, visakhapatnam, India \\ 2Department of Electrical Engineering, Anil Neerukonda Institute of Technology and Sciences, visakhapatnam, India
}

\section{To Cite this Article}

Adarsh. C. Anand and Dr. J. Vijaya Kumar, "Control and Simulation Analysis on Grid Side of a Doubly-Fed Induction Generator Wind Turbine using Different Controllers", International Journal for Modern Trends in Science and Technology, Vol. 07, Issue 01, January 2021, pp.- 128-134.

\section{Article Info}

Received on 11-November-2020, Revised on 02-December-2020, Accepted on 08-December-2020, Published on 17-January-2021.

\section{ABSTRACT}

In today's world scenario electrical energy is playing a crucial and important role in development of any nation. Large and Enormous consumption of non-renewable resources which made them scarce in quantity and increase in cost due to which it has created demand for renewable energy resources. Due to the current requirements for the expansion of renewable energy as sources of electrical energy, wind energy conversion is getting much interest all over the world. The regular traditional wind turbines have fixed turning speeds, while DFIG enables wind turbine to operate in various speeds. In this paper using MATLAB/SIMULINK we study the performance of DFIG using different conventional intelligent controllers. In this paper we use P, PI, PID PI+FUZZY Logic and PID +FUZZY Logic controllers to study the DFIG. The result demonstrates the effectiveness of controllers in boosting the system performance.

KEYWORDS: Wind energy, Doubly-fed Induction Generator, renewable energy, pi, pid, fuzzy.

\section{INTRODUCTION}

Wind power is a renewable energy source that has developed rapidly since the end of the 1970 s. Wind turbines produce clean energy they needn't bother with any fuel transport that can be dangerous to the climate. The sun, the wind and the running water are all the renewable energy sources in contradiction to coal, oil and gas, which rely upon petroleum products from mines or oil and gas fields.

Modern wind turbines are effective, reliable, efficient and produce power at reasonable expense.
The innovation in the wind turbines has developed in few different ways. The control systems have become less expensive and further more advanced, new profiles for the rotor blades can extricate more power from the wind, and new $f$ power electronic gear makes it conceivable to utilize variable speed and to streamline the capacity of the turbines.

A small-scale generation situated at or near the load centers is known as "Distributed Generation". With high availability uncertainties wind power is well known intermittent power source in distributed generation. 
A fixed-speed wind turbine consistently turns at a similar generator/rotor speed during operation, regardless of the wind speed. A variable-speed wind turbine permits the generator/rotor speed to fluctuate relative to wind speed between cut-in and rated speed, along these lines keeping up a steady TSR and optimal aerodynamic performance. Above rated speed, the generator/rotor speed is then held constant. The torque must be actively controlled. DFIG is exposed to numerous constraints, for example, such as the effects of parametric variations and disturbance of the wind speed, which could digress the system from its optimal operation point. Many control strategies of the DFIG have been presented with different control schemes.

Control strategies include the use of conventional controllers such as PID controller and other hybrid connections of controllers. Using these controllers, we control the rotor of the wind system. In this paper we control the wind turbine using different controllers and from the result it is observed that the dynamic performance of DFIG is improved using Hybrid control techniques.

\section{MODELLING OF DFIG}

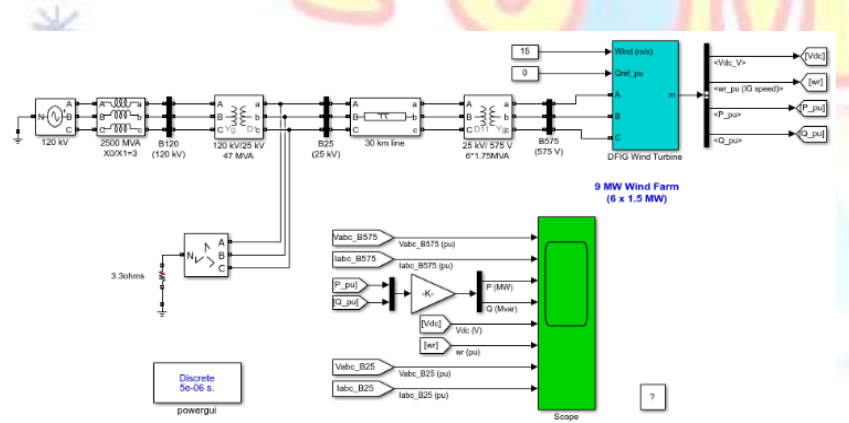

The stator and rotor, flux and voltage equations of a DFIG in the stator voltage in synchronous reference frame is given as:

$$
\begin{aligned}
& v_{s d q}=r_{s} i_{s d q}+j \omega_{e} \psi_{s d q}+\frac{d \psi_{s d q}}{d t} \\
& v_{r d q}=r_{r} i_{r d q}+j \omega_{s t} \psi_{r d q}+\frac{d \psi_{r d q}}{d t} \\
& \psi_{s d q}=L_{s} i_{s d q}+L_{m} i_{r d q} \\
& \psi_{r d q}=L_{r} i_{r d q}+L_{m} i_{s d q}
\end{aligned}
$$

Where $r_{s}=$ stator resistance

$$
r_{r}=\text { rotor resistance }
$$

$\mathrm{s}$ and $\mathrm{r}$ stand for the stator and rotor variable respectively.

$L_{s}=$ stator inductance

$L_{m}=$ magnetizing inductance

$L_{r}=$ rotor inductance

$\omega_{r}=$ rotor speed of the induction machine

$\omega_{s t}=$ slip frequency

$$
\omega_{s t}=\omega_{e}-\omega_{r}
$$

$v_{s d q}=$ stator voltage in d-q reference frame

$$
v_{s d q}=v_{s d}+j v_{s q}
$$

$v_{r d q}=$ rotor voltage in $\mathrm{d}-\mathrm{q}$ reference frame

$$
v_{r d q}=v_{r d}+j v_{r q}
$$

$i_{s d q}=$ stator current in d-q reference frame

$$
i_{s d q}=i_{s d}+j i_{s q}
$$

$i_{r d q}=$ rotor current in d-q reference frame

$$
i_{r d q}=i_{r d}+j i_{r q}
$$

$\psi_{s d s q}=$ stator flux in d-q reference frame

$$
\psi_{s d s q}=\psi_{s d}+j \psi_{s q}
$$

$\psi_{r d s q}=$ rotor flux in d-q reference frame

$$
\psi_{r d s q}=\psi_{r d}+j \psi_{r q}
$$

Now, to get a model of DFIG using active and reactive power, the rotor current will be

from equation (2.15) as: 


$$
i_{r d q}=\frac{\psi_{s d q}-L_{s} i_{s d q}}{L_{m}}
$$

and from equation (2.16) and (2.17), rotor flux is given as:

$$
\psi_{r d q}=\frac{L_{r}}{L_{m}}\left(\psi_{s d q}-L_{s}^{\prime} i_{s d q}\right)
$$

Where,

$$
\boldsymbol{L}_{s}^{\prime}=\left(\mathbf{1}-\frac{\boldsymbol{L}_{m}{ }^{2}}{\boldsymbol{L}_{s} \boldsymbol{L}_{r}} \boldsymbol{L}_{s}\right) \boldsymbol{L}_{s}
$$

Now, by substituting ${ }{ }{ }$ from equation (2.3) in equation (2.2) and then solving equation

(2.1) and (2.2) for ${ }^{i} s d q$, we get:

$\frac{d\left(i_{s d q}\right)}{d t}=\frac{1}{L_{s}^{\prime}} v_{s d q}-\frac{L_{m}}{L_{m}^{\prime} L_{r}} v_{r d q}+\frac{r_{r}-j \omega_{r} L_{r}}{L_{s}^{\prime} L_{r}} \psi_{s d q}+\left(\frac{r_{r} L_{s}+r_{s} L_{r}}{L_{s}^{\prime} L_{r}}+j \omega_{s t}\right) i_{s d q}$

From equation (2.0), substituting $i_{s d}, i_{s q}$ components of $i_{s d q}$ in equation (2.7) and solve it

in term of $p_{s}$ and $q_{s}$ :

$\frac{d\left(p_{s}(t)\right)}{d t}=g_{1} p_{s}-\omega_{s t} q_{s}-g_{4} \psi_{s d}-g_{5} \psi_{s q}+u_{r d}$

$\frac{d\left(q_{s}(t)\right)}{d t}=g_{1} p_{s}+\omega_{s t} q_{s}-g_{5} \psi_{s d}-g_{4} \psi_{s q}+u_{r q}$

$$
\text { Where, } u_{r d}=g_{2} v_{r d}+g_{3} v_{r q}-\frac{3\left|v_{s}\right|^{2}}{2 L_{s}^{\prime}}
$$$$
u_{r q}=g_{3} v_{r d}-g_{2} v_{r q}
$$

$$
g_{3}=\frac{3 L_{m} v_{s q}}{2 L_{s}^{\prime} L_{r}}
$$

$$
g_{4}=\frac{3}{2}\left(\frac{r_{r} v_{s d}-L_{r} \omega_{r} v_{s q}}{L_{s}^{\prime} L_{r}}\right)
$$

$$
g_{5}=\frac{3}{2}\left(\frac{r_{r} v_{s q}-L_{r} \omega_{r} v_{s d}}{L_{s}^{\prime} L_{r}}\right)
$$

Solving the stator voltage equations for $\psi_{s d q}$

$$
\frac{d\left(\psi_{s d}\right)}{d t}=v_{s d}+\omega_{e} \psi_{s q}+\frac{2 r_{r}}{3\left|v_{s}\right|^{2}}\left(v_{s d} p_{s}+v_{s q} q_{s}\right)
$$

$$
\frac{d\left(\psi_{s q}\right)}{d t}=v_{s q}-\omega_{e} \psi_{s d}+\frac{2 r_{s}}{3\left|v_{s}\right|^{2}}\left(v_{s q} p_{s}+v_{s d} q_{s}\right)
$$

The machine's electromechanical dynamic model is given as:

$$
\frac{d \omega_{r}}{d t}=\frac{P}{J}\left(T_{e}-T_{m}\right)
$$

$\mathrm{P}=$ No. of pole pairs

$\mathrm{J}=$ Rotor inertia

$T_{m}=$ Input mechanical torque of the machine

$T_{e}=$ electrical torque of the machine

$$
T_{e}=\frac{3 P}{2}\left(\psi_{s d} i_{s q}-\psi_{s q} i_{s d}\right)
$$

By substituting for $i_{s q}$ and $i_{s d}$ from equation (2.0) in equation (2.14) and then putting the

$$
\begin{aligned}
g_{1} & =-\frac{r_{r} L_{s}+r_{s} L_{r}}{L_{s}^{\prime} L_{r}} \\
g_{2} & =\frac{3 L_{m} \nu_{s d}}{2 L_{s}^{\prime} L_{r}}
\end{aligned}
$$

$$
\frac{d \omega_{r}}{d t}=g_{6} p_{s}+g_{7} q_{s}-\frac{P}{J} T_{m}
$$

Where, 


$$
\begin{aligned}
& g_{6}=\frac{P^{2}}{J}\left(\frac{\psi_{s d} v_{s q}-\psi_{s q} v_{s d}}{\left|v_{s}\right|^{2}}\right) \\
& g_{7}=\frac{P^{2}}{J}\left(\frac{\psi_{s d} v_{s q}+\psi_{s q} v_{s d}}{\left|v_{s}\right|^{2}}\right)
\end{aligned}
$$

The Matrix model of the Doubly-Fed induction machine is shown below in state variable matrix form is obtained from equation (2.8) to (2.13) and (2.16), is given as:

$\frac{d}{d x}\left[\begin{array}{l}p_{s} \\ q_{s} \\ \psi_{s d} \\ \psi_{s q} \\ \omega_{r}\end{array}\right]=\left[\begin{array}{ccccc}g_{1} & -\omega_{s l} & -g_{4} & -g_{5} & 0 \\ \omega_{s l} & g_{1} & -g_{5} & g_{4} & 0 \\ 2 r v_{s d} & 2 r_{s} v_{s q} & 0 & \omega_{e} & 0 \\ 3\left|v_{s}\right|^{2} & 3\left|v_{s}\right|^{2} & & & \\ 2 r_{s} v_{s q} & \frac{-2 r_{s} v_{s d}}{3\left|v_{s}\right|^{2}} & -\omega_{e} & 0 & 0 \\ g_{1} & g_{1} & 0 & 0 & 0\end{array}\right]\left[\begin{array}{l}\left.p_{s}\right|^{2} \\ q_{s} \\ \psi_{s d} \\ \psi_{s q} \\ \omega_{r}\end{array}\right]+\left[\begin{array}{l}u_{r d} \\ u_{r q} \\ v_{s d} \\ v_{s q} \\ -\frac{P^{2}}{J} T_{m}\end{array}\right]$

The above model of DFIG we got, is a nonlinear dynamic model because the coefficients of the matrix input are functions of the state variables.

III. MODELLING OF GRID SIDE CONVERTERS

The equivalent circuit diagram of GSF in the synchronous reference frame is shown below.

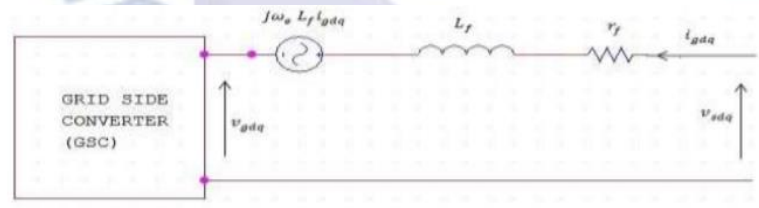

Figure1 Equivalent circuit diagram of grid side filter

The model of the grid-side converter and filter in $\mathrm{dq}$ reference frame is given as:

$$
v_{s d q}=v_{g d q}-r_{f} i_{g d q}+j \omega_{e} L_{f} i_{g d q}+L_{f} \frac{d i_{g d q}}{d t}
$$

Here subscript "g" means the variables at the network side converter.

Where, ${ }_{f}=$ resistance of the filter

$$
L_{f}=\text { inductance of filter }
$$

From above equation, substituting $i_{g d}, i_{g q}$ components of $i_{g d q}$ in equation (3.0) and solve in term of $p_{g}$ and $q_{g}$ we obtain:

$$
\frac{d}{d t}\left[\begin{array}{l}
p_{g}(t) \\
q_{g}(t)
\end{array}\right]=\left[\begin{array}{cc}
-\frac{r_{f}}{L_{f}} & -\omega_{e} \\
\omega_{e} & -\frac{r_{f}}{L_{f}}
\end{array}\right]\left[\begin{array}{l}
p_{g}(t) \\
q_{g}(t)
\end{array}\right]+\left[\begin{array}{l}
u_{g d} \\
u_{g q}
\end{array}\right]
$$

Where

$$
\begin{aligned}
& u_{g d}=\frac{3}{2 L_{f}}\left(\left|v_{s}\right|^{2}-\left(v_{s d} v_{g d}+v_{s q} v_{g q}\right)\right) \\
& u_{g q}=\frac{3}{2 L_{f}}\left(v_{g q} v_{s d}-v_{g d} v_{s q}\right)
\end{aligned}
$$

The dc-link model is obtained as:

$$
v_{d c}(t) I_{d c}(t)=p_{g}(t)-p_{r}(t)-p_{\text {loss }}(t)
$$

Where $p_{g}(t)=$ the real power that converter gives to the rotor

$$
\begin{aligned}
& p_{\text {loss }}(t)=\text { total power loss of the filter } \\
& p_{r}(t)=\text { the rotor power }
\end{aligned}
$$

The real power to the rotor is:

$$
p_{r}(t)=\frac{3}{2}\left(v_{s d} i_{r d}+v_{s q} i_{r q}\right)
$$

From equation (2.5) and (2.0), $p_{r}$ is expressed as: $p_{r}=\frac{L_{s}}{L_{m}}\left(\frac{v_{s d} v_{r d}+v_{s q} v_{r q}}{\left|v_{s}\right|^{2}}\right) p_{s}+\frac{L_{s}}{L_{m}}\left(\frac{v_{s d} v_{r d}-v_{s q} v_{r q}}{\left|v_{s}\right|^{2}}\right) q_{s}+\frac{3 v_{r d}}{2 L_{m}} \psi_{s q}+\frac{3 v_{r d}}{2 L_{m}} \psi_{s q}$

Since dc link current expression is given by:

$$
I_{s c}(t)=C \frac{d V_{d c}(t)}{d t}
$$

In above equation by substituting the value of $d c$ link model is deduced as: 


$$
\frac{d V_{d c}(t)}{d t}=\frac{I_{d c}(t)}{C}=\frac{p_{g}(t)-p_{r}(t)}{C V_{d c}}
$$

\section{CONTROL OF DFIG}

Proportional Integral (PI) Controller

The proportional integral controller produces an output, which is the combination of outputs of the proportional and integral controllers.

$u(t)=K_{p} e(t)+\int e(t) d t$

Apply Laplace transform on both sides -

$U(s)=\left(K_{p}+\frac{K_{I}}{s}\right) E(s)$

$\frac{U(s)}{E(s)}=K_{p}+\frac{K_{I}}{s}$

Therefore, the transfer function of proportional integral controller is $K_{p}+\frac{K_{I}}{s}$.

The block diagram of the unity negative feedback closed loop control system along with the proportional integral controller is shown in the following figure.

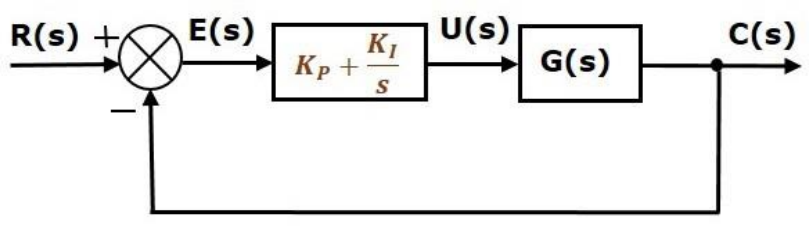

Figure 3 Proportional Integral Controller

The proportional integral controller is used to decrease the steady state error without affecting the stability of the control system.

Proportional Integral Derivative (PID) Controller

The proportional integral derivative controller produces an output, which is the combination of the outputs of proportional, integral and derivative controllers.

$u(t)=K_{p} e(t)+K_{I} \int e(t) d t+K_{D} \frac{d e(t)}{d t}$

Apply Laplace transform on both sides -

$\frac{U(s)}{E(s)}=K_{p}+\frac{K_{I}}{s}+K_{D} s$

$U(s)=\left(K_{p}+\frac{K_{I}}{s}+K_{D} s\right) E(s)$
Therefore, the transfer function of the proportional

integral derivative controller is

$$
K_{p}+\frac{K_{I}}{s}+K_{D} s
$$

The block diagram of the unity negative feedback closed loop control system along with the proportional integral derivative controller is shown in the following figure.

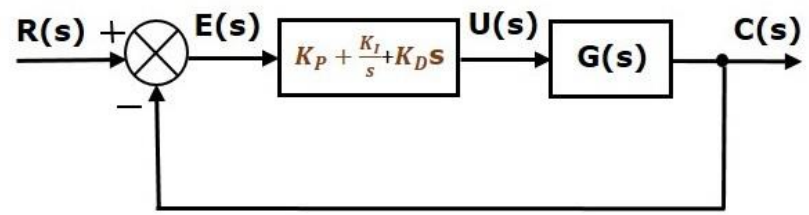

Figure 4 Proportional Integral Derivative Controller

The proportional integral derivative controller is used to improve the stability of the control system and to decrease steady state error.

\section{INTELLIGENT CONTROLLERS}

A fuzzy control system is a control system based on fuzzy logic, a mathematical system that analyses analog input values in terms of logical variables that take on continuous values between 0 and 1 , in contrast to classical or digital logic, which operates on discrete values of either 1 or 0 (true or false, respectively).

\section{SIMULATION RESULTS AND DISCUSSION}

\section{ACTIVE POWER}

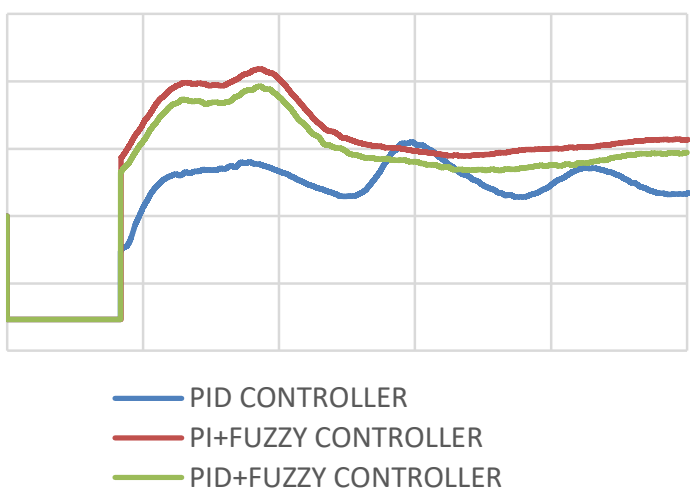

Active power of the controllers 


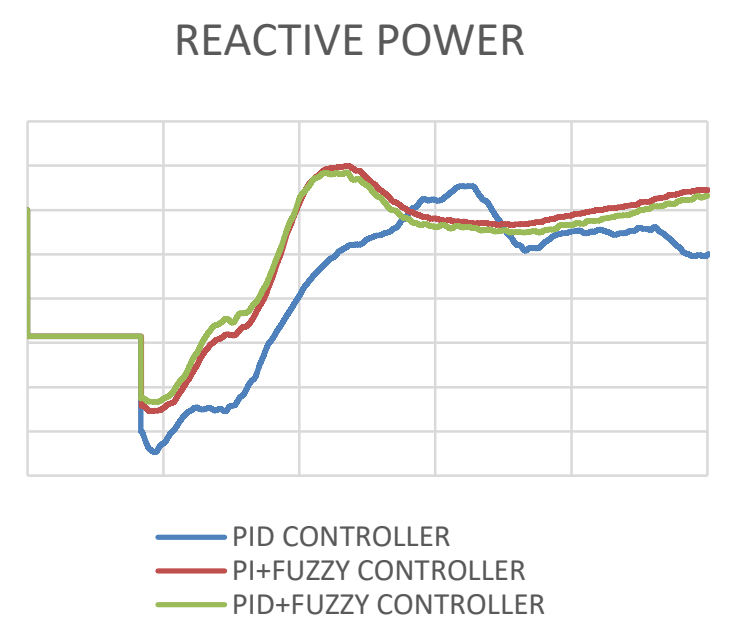

Reactive power of the controllers

\section{VOLTAGE}

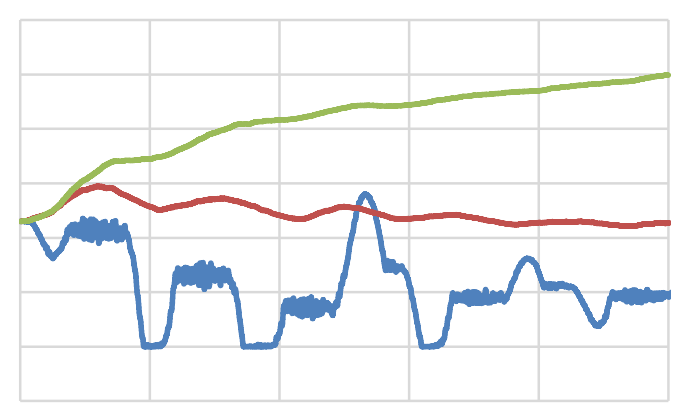

PID CONTROLLER

PI+FUZZY CONROLLER

PID+FUZZY CONTROLLER

\section{Voltage of the controllers}

To accomplish the control of DFIG based wind turbine, DFIG was converted into its equivalent mathematical model and the grid side converter is] modelled in d-q axis and controllers were added through MATLAB program. The tabular result shows the numerical comparison of P,PI,PID, and combination of above controllers with fuzzy.

\begin{tabular}{|c|c|c|c|c|}
\hline & & $\begin{array}{l}\text { Rise } \\
\text { time }\end{array}$ & $\begin{array}{l}\text { Peak } \\
\text { time }\end{array}$ & $\begin{array}{l}\text { Settling } \\
\text { time }\end{array}$ \\
\hline \multirow[t]{3}{*}{$\begin{array}{l}\text { PID } \\
\text { controller }\end{array}$} & $\begin{array}{l}\text { Active } \\
\text { power }\end{array}$ & 0.02 & 0.15 & 0.17 \\
\hline & $\begin{array}{l}\text { Reactive } \\
\text { power }\end{array}$ & 0.02 & 0.05 & $0.14 \quad[10]$ \\
\hline & Dc-voltage & 0.01 & 0.04 & 0.15 \\
\hline \multirow[t]{3}{*}{$\begin{array}{l}\text { PI+Fuzzy } \\
\text { controller }\end{array}$} & $\begin{array}{l}\text { Active } \\
\text { power }\end{array}$ & 0.17 & 0.038 & 0.055 \\
\hline & $\begin{array}{l}\text { Reactive } \\
\text { power }\end{array}$ & 0.022 & 0.043 & 0.057 \\
\hline & Dc-voltage & 0.01 & 0.013 & 0.1 \\
\hline PID+Fuzzy & Active & 0.016 & 0.036 & 0.056 \\
\hline
\end{tabular}

\begin{tabular}{|l|l|l|l|l|}
\hline controller & power & & & \\
\cline { 2 - 5 } & $\begin{array}{l}\text { Reactive } \\
\text { power }\end{array}$ & 0.02 & 0.045 & 0.055 \\
\cline { 2 - 5 } & Dc-voltage & 0.002 & 0.1 & 0.1 \\
\hline
\end{tabular}

\section{CONCLUSIONS}

Control and performance analysis for a doubly-fed induction generator wind turbine using different controllers is researched based on the simulation study made on grid side control of DFIG wind generation system. The study is made using different controllers connected to the DFIG wind turbine. Here in this project P, PI, PID, PI+FUZZY and PID+FUZZY controllers are used to analyze and understand the differences. While the fuzzy controller has a strong robustness to control the system whose parameters are varied. From the result it is observed that fuzzy controlled hybrid system gives better performance compared to other individual controllers.

\section{REFERENCES}

[1] N.R.Babu and P.Arulmozhivarman," Wind energy conversion systems a technical review," Journal of Engineering Science, Vol 8, NO.4,2013.

[2] A.P. Varma and K.B.Chakri," Study of grid connected induction generator for wind power application, "National Institute of Technology,Rourkela,2012.

[3] B. Pokharel," Modelling control and analysis of a doubly-fed induction generator based on wind turbine system with voltage regulation", PROQUEST LLC,2012.

[4] L. A. Salomao and H.G. Cuatzin," Fuzzy-PI control, PI control and Fuzzy Logic control comparison applied to a fixed speed horizontal axis 1.5 MW wind Turbine" Proceedings of the World Congress, San Francisco, PP.24-26, Vol II, October2012.

[5] Tapia, A., Tapia, G., Ostolaza, J.X. and Saenz, J.R. Modeling and control of a wind turbine driven doubly fed induction generator, IEEE Transactions on Energy conversion, vol. 18, No. 2, June 2003.

N. Sonker, Soumya Rajan Das, L. Mahapatro, "MODELLING AND SIMULATION OF DOUBLY-FED INDUCTION GENERATOR CONNECTED WITH WIND TURBINE" National Institute of Technology, Rourkela,2015

H.C.Chen and P.H.Chen, "Active and reactive power control of doubly fed induction generator", International Journal, PP. 117-124, No.1L, April 2014.

A.Petersson "Analysis, Modeling and Control of Doubly Fed Induction Generators for Wind Turbines" Ph.D dissertation, Electr. Power Engg, Chalmers Univ. Tech., Sweden, 2005.

E. M.Tayeb and A.T. Ali,"Comparison of some classical PID and fuzzy logic controllers", International Journal of Scientific, Volume 3, Issue9, September 2012.

A.Petersson, T. Thiringer, L. Harnefors, and T. Petru, "Modeling and experimental verification of grid interaction of a DFIG wind turbine," IEEE Trans. Energy Convers., vol. 20, no. 4, pp. 878-886, Dec. 2005.

S. R. Karpe, B. N. Bedre and V. P. Dhoto "Doubly fed induction generator in wind mill", International Journal of Emerging Trends, (IJETTCS) Volume 2, Issue 4, July-August 2013.

N. Kumar and R A. JASWL, "Development of fuzzy controller for DFIG connected to wind turbine ", IJEEE, International Academy of science, IASET, India, vol.5, issue4, 2016. 